\title{
A Comparative Study of Perfect Aspect Category in English and Chinese
}

\author{
Manfu Duan \\ Foreign Languages Research Institute, Beijing Foreign Studies University, Beijing, 100089, China; \\ English Department, Foreign Languages College, Inner Mongolia University, Hohhot, 010021, China
}

\begin{abstract}
Based on the definitions of "category" and "aspect", the article analyzes the similarities and differences between English and Chinese perfect aspect in terms of formation, meaning, and usage. Main findings are that in the first place the perfect aspect in both English and Chinese expresses the same basic meaning, and it can be used to show the accomplishment of an action, the duration of an action as well as the anteriority of an action; secondly, the perfect aspect in English must be realized by grammatical device, but that in Chinese can be realized by means of grammar together with the lexical device; thirdly, there exist differences between English perfect aspect and that in Chinese in some specific usages. The study will be of benefit to have a deeper understanding of aspect as a grammatical category, and a more skillful application of English aspect and Chinese aspect. In the meantime, such analysis will deepen the understanding of differences of grammatical category between languages and the linguistic universality and diversity.
\end{abstract}

Index Terms—English, Chinese, aspect, perfect, comparison

\section{INTRODUCTION}

English and Chinese are of different language families. English belongs to the Indo-European Language Family, while Chinese to the Han-Tibetan Language Family. English is between an analytic language and a synthetic language, whereas Chinese is the most typical analytic language. They are different at all levels, especially in terms of the form, meaning and function of grammatical categories. A comparison of English and Chinese can reveal the similarities and differences between them, and deepen the understanding of Chinese and English. This paper will first define the concept of category and aspect, and then compare and analyze English perfect aspect and Chinese perfect aspect from the perspectives of form composition, meaning expression and specific use so as to find out the similarities and differences between them and to analyze the cause of differences, thus achieving a new understanding of English perfect aspect and Chinese perfect aspect and also of the grammatical category aspect.

\section{CATEGORY AND ASPECT}

Categorization is a complicated activity of human cognition. It is a process where human brain converts the world into orderly information by means of a system of symbols. It is a mental process of classification and is the basis of construal category (Ungerer E. \& H. J. Schmid 2001, p.2). In this process, human beings use their own subjective initiatives to classify the objective things in the process of interaction with the objective things and give the world certain structure. The result of such classification is category. Category is the result of categorization and is also the starting point of semantic and conceptual formation.

Also, people classified many categories of the language they use. In his Introduction to Theoretical Linguistics, Lyons(1968) classifies three major grammatical categories, "the primary grammatical category are word classes, and the secondary grammatical categories are grammatical features of the word classes, such as gender, number, case, tense, aspect and voice, while sentence constituents like subject, predicate and object belong to the functional categories." According to such a classification, aspect is a secondary grammatical category, which also can be called specific grammatical category.

Aspect was originally put forward as a category in general linguistics, but not specific to any particular language. Aspect, as a grammatical category in general linguistics, is indicated mainly by changes of verb forms. However, different languages vary greatly in the way the aspect is expressed. Some inflected languages like Russian and Bulgarian which belong to the Slavic languages have rich forms to show aspect. English is between an analytic language and an inflectional language. Without special form to show aspect, English resorts to inflectional changes of adding auxiliary verbs to verbs to indicate aspect. Chinese is a language without inflectional changes, so aspect is revealed by semi-dependent function words.

\section{Aspect, CAtegory AND Perfect Aspect CATEGory IN ENGLish}

Traditional English grammar regarded the prescriptive Latin grammar as a model, in which no distinction is made between tense and aspect, and only tense is emphasized while aspect is always ignored. It assumed that aspect is 
included in tense. There is no exaggeration that it is an oversight in the field of linguistics and leads us to a vague understanding of aspect and a confused use of terminology. As a result, we cannot explain scientifically and reasonably some grammatical phenomena that are related with aspect. This paper tries to analyze aspect of English from different perspectives and tries to work out a clear relational schema between different aspects. Therefore, we could have a more clear understanding of aspect.

In English, aspect is first a grammatical category of verb. It presents the inner time structure of a certain event. Aspect is different form tense: tense is used to describe the relationship between the time an action occurred or a state existed and the time of speaking, whereas aspect uses specific verb forms to show situations of action and process in a situation within a certain time and also to show methods for carrying out actions. For example, it can be used to indicate whether the action is going on or has been completed; whether it is continuous, transient or repetitive.

Aspect is also a semantic concept. Semantic aspect is the inherent property of the action expressed by verb or verb phrase. A verb itself contains the necessary time on which the action expressed by the verb rely, namely, the "implicit time". A verb has certain properties of aspect. "Aspect property is the lexical-semantic category of English verb, and it is the situation type of verb or verb centric phrase and it is about the type of the inner structure of situation, primary of the inner time structure" (Yi 1999, p.158). "Grammatical aspect reveals the speaker's different ways of observance towards the inner time structure of the situation, while semantic aspect is determined by other constituents of the sentence" (Olsen 1997).

Despite the objective existence of difference between the two aspects, there is no strict distinction in literatures, and many authors tend to blend the two ( $\mathrm{Gu}$ 1998, p.193). Studies in recent years regard the features of aspect as the features of the whole sentence rather than the features of words. This feature is produced under the joint action of verb aspect property and verb aspect (grammatical aspect). Zhang Jin and Chen Yunqing (1981, p.310) once remark that the situational meaning (aspect property meaning, the author's note) expressed by the predicate of a sentence is often the algebraic sum of verb aspect property and verb aspect.

As for how many types of aspect there are in English, there is no consistent view among grammarians, because when aspect is classified, some are classifications of grammatical aspect and others are classifications of semantic aspect. For example, Frawley (1992, p.294) thinks that there should be six kinds of aspects: perfective/ imperfective, punctual/ durative, iterative, telic/ atelic, progressive and habitual. Grammarians like Quirk only make a distinction between perfective and progressive. Still there are books using such dichotomy as perfective and imperfective. This paper will only discuss grammatical aspect and accept the dichotomy as perfective and imperfective in English and will only focus on English perfective aspect. During the process of discussion, the aspective character of verb may be related.

What is perfect aspect then? Longman Dictionary of Language Teaching and Applied Linguistics defines perfective as "(in grammar) a kind of aspect that indicates the relationship between a state or event" (Richards 2000, p.337). Simply speaking, the meaning of perfective aspect is that the action was fully presented before the reference time. If the reference time is the speaking time, it is present perfect; if the reference time is a time point in the past, it is present perfect; if the reference time is one in the future, it is future perfect. They are respectively expressed as "have (has) + done", "had + done" and "will have + done". Among the three perfective aspects, present perfect is frequently used and it is more important than the other two kinds of perfect either in meaning expression or in frequency of use.

Present perfect aspect in English has two main usages, one of which is to express the association between actions happened in the past and the present. As the following examples show:

(1) a. Professor Wang has left for Beijing for a conference.

b. I've closed the window.

c. The price of vegetables has increased rapidly these days.

d. He's traveled a lot.

e. I've told you about it, but you did not listen.

In example (1a), has left expresses the action happened in the past, and the result is that Professor Wang now is not at the place where the speech took place. It can be shown that present perfect is an aspect which is concerned with two time periods, of which one refers to some time in the past, and the other refers to present time, and they are closely related. Although the action that is expressed by present perfect aspect happened in the past, it is an aspect with retrospective meaning. We can find this feature from the following aspects: the model verb have (has) expresses the present tense and it can be used together with temporal adverbials including the present time, such as now, today, this week, these days, and so forth; what's more, it cannot be used with phrases expressing the past time, such as just now, yesterday, three days ago, last year, etc. As the present perfect aspect belongs to the present tense, the emphasis of employing the present perfect lies not in the action that happened in the past and the time when it happened (such usage is not in collocation with any adverbials of time) but in the result or influence of this action to the present time, and sometimes the result or influence is direct and specific. For instance, in example (1b), the direct and specific influence of I've closed the window is that "the window is now closed". For another example, in The price of vegetables has increased rapidly, the direct result is that "the price of vegetables is rather high now." Sometimes, the result is indirect, for instance, in (1d) He's traveled a lot, one possible result is "He has seen a lot and known many things". Apparently, the result is indirect. But sometimes, the action is over and the situation has changed, so the result no longer exists. For example, in example (1e) I've told you about it, but you did not listen, the result of the behavior "telling" no longer 
exists, so it becomes only an experience in the past.

The second usage of present perfect is to express the duration of an action. As the following examples show:

(2) a. I've stayed here for about three months.

b. He has been a teacher in the Inner Mongolia University since 1996.

c. The family have enjoyed better health since they moved to the countryside.

d. I've been here for three hours. I have to leave now.

e. You have watched TV too long, so you'd better have a rest.

In the above examples, "stayed", "has been", and "have enjoyed" are showing the duration of actions, of which several actions and states started from a certain past time and lasts to the present time. In addition, in general, the actions will continue, as in the examples of (2a), (2b), and (2c). If the relationship of co-text is clear, the actions will not continue, as in the examples of (2d) and (2e). We can find out that the verbs of such usage are all durative verbs and they generally collocate with the structures of "for+ a period of time", "since+ the past time", and "since+ the clause with the past tense". That is to say, the grammatical marker of present perfect is to be concert with the aspect of the verbs used. The aspects of non-durative verbs contradict the meaning of duration expressed by perfect aspects, so they cannot be applied in these sentences. But there is an interesting phenomenon that the negative forms of such verbs can be employed in such present perfect. As the following examples show:

(3) a. * I've bought the stereo for one year.

b. I've not bought anything for three months.

c. * I've come here for two weeks.

d. I've not touched any beer for a whole week.

In fact, non-durative verbs represent actions, and their negative forms can represent a state of duration; for instance, the verb marry is a non-durative verb, but don't marry show a durative state. Therefore, in the place of durative verbs, the negative forms of non-durative verbs can be used, too. It can be seen from the above examples (3a) and (3c), the Chinese translations of these two sentences are correct while their English counterparts are incorrect. This shows that Chinese grammar of aspect is not as rigid as English grammar.

The above two usages are the typical usage of present perfect. Besides, there are some marginal non-typical usages of present perfect. The present perfect is used in the compound sentences with adverbial clause of time and condition with the coordination of tense of the main clause (the simple future tense) to express "the actions that has finished before a future action". On such occasion, present perfect is only to express "anteriority", and it has no relation with "the present" as the following example (4) shows:

(4) a. I will go to see the film as soon as I've finished my homework.

b. When we've finished the project, we'll go on a vacation.

Contrary to such a usage, if the present perfect is applied in the main clause, the subordinate clause uses the simple present tense. And it expresses an "occasion that often appears", and it has no certain time concept as the example (5) show:

(5) a. When a man goes back to look at the house of his childhood, it has always shrunk.

b. Once we realize the truth, we've gained freedom.

Another special usage of present perfect is to express that "somebody has done something for several times" as the example (6) shows:

(6) a. It's the first time I've been here.

b. It is the second time he has been out with her.

In English, the uses of past perfect and future perfect are basically the same as present perfect. The differences lie in different reference time points, in which past perfect regards some time point in the past as reference point, and future perfect regards some time point in the future as reference point. Here the author will not discuss it in detail.

\section{ASPECT AND PERFECTIVE IN CHINESE}

The research about aspect in Chinese is less developed than in English. Moreover, a great divergence exists in many ways; for example, whether there is aspect, the name of aspect, the range of aspect in Chinese, the property of Chinese character reflecting aspect including 着, 了, 过 and so on (Wan 1996). According to Hu Zhuanglin (1990), the studies on aspect in Chinese can be basically classified into three types:

The first type does not talk about the grammatical category aspect and it just divides time auxiliaries 着, 了, 过 and so on expressing the progress of action in auxiliary words item. This type is more or less equal to perfective and imperfective in English.

The second type is represented by Zhao Yuanren. He thinks there is aspect in Chinese and comes up with the explicit concept "suffix of verb aspect". These suffixes which can be added to all the verbs are unlimited and have very few forms. The aspect in Chinese is not restricted to the dichotomy of perfective and progressive in English. In Chinese there are seven types of aspects: zero aspect, perfective, progressive, infinitive past aspect, and durative.

The third type is represented by Halliday's model which thinks the suffixes of perfective and imperfective semantic aspect are 着, 了, and 过. Modal particles having perfective and imperfective meanings are 啦, 来着 and 呐. They 
are corresponding to aspects.

Now the opinion people usually accept is that there are perfective, progressive and experiential aspects in Chinese, whose symbols are respectively 着, 了 and 过. This paper also accepts this opinion. Unlike the aspect system in English, aspect system of Chinese is still not fixed and has a great divergence. For convenience of discussion, here this paper will use $V+了(l e)$ to indicate the perfective in Chinese aiming to correspond with the perfective have+done in English.

Now we talk about the properties of the character $了$. What we discussed above is grammatical aspect and grammatical category. Grammatical category is based on the inflectional Indo-European Language. Gao Mingkai (1957, p4) also said, "Narrowly speaking, grammatical category refers to the summary of those grammatical meanings expressed by all the inflections of nouns, verbs, and adjectives that grammarians usually discussed in word classes." But the main feature of Chinese is that there are no strict inflections. Like the grammatical category of aspect, there are many means of expression in Chinese, including the repetition, substantive use, zero form of verb. Besides, others are words with adhesiveness, among which aspect auxiliary or modal particle is recognized as half independent word (Zuo 1997, p111). $了$ is undoubtedly a modal auxiliary expressing perfective. Its attached object is not only a verb, but also an adjective, a predicative phrase and a sentence, as can be illustrated by example (7):

(7) a. 他今天干了一件漂亮的事情。(了 is attached to the verb concerned.)

b. 保姆擦干净了地面。(了 is attached to an adjective concerned.)

c. 今天星期五了。(了 is attached to a nominal predicate.)

d. 经过几小时颠簸, 我终于回到家了。(了 is attached to the end of the sentence.)

The perfective in Chinese has basically three uses. The main use is to express the completion of action, i.e., the effect and result of the action that has happened, as can be shown by example (8):

(8) a. 我把窗户关上了。(The window is closed at the moment of speaking.)

b. 他来了。(He is at the place of speaking.)

c. 我们赶到车站时, 火车已经开了。(The train has left the station.)

d. 修建的大楼今天完工了。(The building is in shape now.)

The second use of perfective in Chinese is to express the anteriority of the action. $V+l e$, unlike what some scholars said, is to express past tense. The anteriority that it expressed is the past which regards reference time point as reference, i.e., the action happened before the reference time point. Moreover, this reference point can be present, past or future. There is no grammatical category tense in Chinese, but vocabulary can be used to express relative time relation. Example (9):

（9） a. 他已经做完了作业。（relative “present"）

b. 今年雨水多, 五月前就下了两场雨。(relative to “past”)

c. 明天等你来的时候, 我早就走了。(relative to “future")

d. 你明年毕业了, 分配了工作, 我就放心了。(relative to “future")

But it can not be denied that $了$ indeed can be used in the sentence of past tense. So what are the differences between the past tense sentences with "le" and the present perfect aspect sentences with $V+\mho$ ? Differences exist, but not too big. $V+\checkmark$ form is established in seeing the past from the present while the past tense is based on the past radically. Example (10):

(10) a. 他昨天完成任务了。(past tense, focus on “past")

b. 他昨天完成了任务。(现在完成体，立足于现在）

c. 今天早晨下雨了。(past tense, focus on "past")

d. 今天早晨下了一场雨。(present perfective, focus on "present")

There is another use of perfective in Chinese, expressing the continuing of action or state, example (11):

(11) a. 这件事我后悔了好几年, 现在提起来仍然觉得很遗憾。

b. 我祖父去世好几年了。

c. 我来北京快四个月了。

Now we will analyze temporal adverbial types occurring with the perfective in Chinese. Occurring with the first two uses are adverbials of time with certain time point, including past adverbials of time, for example, (10b) and (10d); without adverbials of time, it expresses the time point of speaking, such as, example (9a). Because the first kind of usage expresses the completion of specific action and the time must be certain; the second kind of usage expresses the anteriority and there must be a specific time reference point, or there is no "anteriority". The third kind of usage usually uses with the adverbials of time showing a period of time, such as, example (11), and it also can uses with uncertain 
adverbials of time, such as example (12):

(12)什么时候复习完了功课, 就什么时候叫你出去玩。

\section{Comparative Analysis of Perfective AsPeCt Between ENGlish AND ChInESE}

After analyzing the use and characteristics of English and Chinese perfective aspects, we will summarize the similarities and differences between them.

It can be seen that the meanings expressed by English perfective and Chinese perfective are almost the same with the same function of indicating completion (the influence on present), lasting and present, which means that the meanings that can be expressed by English perfective can also be expressed by Chinese perfective. This can be thought as a kind of reflection of language universality. Meanwhile, it indicates that aspect is rather a semantic concept actually.

Nevertheless, it should not be neglected that there are also many distinctions between English and Chinese perfective aspects. Firstly, the perfective aspect in English must be expressed by particular grammatical forms, the morphological changes of verb. Aspect is prescriptive or obligatory. In order to express completion of an action, the verb must be used in the form of have + done, and the concept of tense which is combined with perfective aspect will be expressed through auxiliary verbs such as have, had and will. However, in Chinese, although the character $了$ is a marker of perfective, not all perfective aspects have to use this character. Sometimes, the perfectives can be shown through words. Aspect in Chinese is neither prescriptive nor obligatory and the concept of tense combined with perfective in Chinese is usually indicated through adverbial clause of tense. For example, although the sentences below express the same meaning, some use the character $了$ while others do not:

(13) a. 我刚吃了饭。(perfective aspect of using character 了)

b. 我刚吃完饭。(without 了, but 完 indicates the same perfective meaning)

c. 我刚吃完了饭。( using both perfective marker “了” and word 完)

(14) a. He has been monitor since he entered the university.

b. 自从他上大学以来就一直当班长。(Chinese perfective aspect without 了)

However, in most cases, the Chinese perfective aspects without $了$ are incorrect or incomplete. For example (15):

(15) a. ? 修建的大楼今天完成。

b. 修建的大楼今天完成了。

(15a) makes people have a feeling of not finishing and it is rather an imperative sentence than a perfective aspect. Besides, in negative sentences of Chinese perfectives, 了 is usually not used. It is correct to add 没(有) only while the corresponding parts in negative English perfectives have to use have like the positive ones, like example (16):

(16) a. 昨天下了一场雨。

b. 昨天没有下雨。(to negate with “没有”, without “了” followed)

c. It has rained a lot this summer.

今年夏天下了很多雨。

d. It has not rained a lot this summer. (to negate with "has not")

今年夏天没有下很多雨。

Secondly, although the meanings expressed by English and Chinese perfectives are almost the same, the two perfectives are not identical in using aspect. In another words, the English perfective can be expressed in other ways in Chinese and vice versa. We can make appropriate adaptations according to each language habit when translating. For instance, Chinese differentiate perfective aspect and realizing aspect with markers of $V+\mathcal{J}$ and $V+$ 过, but the meanings of both the two aspects can be expressed by perfective aspects in English, like the example (17):

(17) a. He has been to Beijing.

b. He has gone to Beijing.

c. 他去过北京。

d. 他去了北京。

Apparently, (17c) is the right translation of (17a) and (17d) is the right translation of (17b). Both English sentences of (17a) and (17b) use perfective aspect, and the differences of meanings are shown with different verbs. However, (17c) uses Chinese experiential aspect while (17d) uses Chinese perfective aspect.

There are not enough forms to express TENSE and ASPECT separately, so the two grammatical categories are expressed with same forms. They are marked by the verbs in same ways. Taking the perfective of have done as an example, if our minds focus on the time when the action happened, it expresses that the action happened before the reference moment, that is TENSE; if our minds focus on the process, it expresses that the action was finished before the reference moment, that is ASPECT. There is only grammatical category to express ASPECT but no one to express TENSE in Chinese. So, sometimes, if an English sentence intends to emphasize that an action happened in the past, it will use past simple directly while the corresponding Chinese translation will use perfect aspect. For example (18):

(18) a. He lost two sons in the war. (English past simple) 
b. 在战争中他失去了两个孩子。(Chinese perfect aspect)

Finally, the adverbials of time appear with perfect aspects are almost the same in English and Chinese but there is one difference. The adverbial of time which indicates "past" can appear in Chinese perfectives. However, it can not be used in English perfective sentences. If it needs to be used, the sentence should be in past simple form, like example (19):

(19) a. It rained yesterday.

b. 昨天下了一场雨。( “昨天”is used in perfective sentence)

\section{DISCUSSION}

Based on the above comparative analysis, we can see that although the meanings expressed by English and Chinese perfect aspect are almost the same, their usages do not correspond with each other; as a kind of grammatical category, English and Chinese perfect aspects have typical usages and marginal usages respectively; both English and Chinese perfect aspects have fixed ways of expression, but the use of English perfect is obligatory, while Chinese can also use lexical means to express perfect aspect; besides, in perfective sentences, verbs with different semantic aspects can be used in English and Chinese.

Through the comparison of English and Chinese perfect aspects, we can see the similarities between the two languages and the particularities of each language. Aspect is rather a semantic concept with universality and it can be expressed in every language. However, when expressing the same meaning, different languages can employ different ways, using grammatical method or lexical method. Meanwhile, the meanings expressed by one grammatical category are not the same in different languages, which shows that the users of different languages have different ideas when observing and classifying the world.

\section{REFERENCES}

[1] Frawley, W. (1992). Linguistic Semantics. New Jersey: Lawrence Associates Inc. Publisher.

[2] Gao Mingkai. (1957). On Chinese Grammar. Beijing: Science Press.

[3] Gu Yang. (1998). Aspect and Tense of Verb. In (Xu Liejiong eds) Universality and Particularity. Beijing: Beijing Language and Culture University Press.

[4] Hu Zhuanglin. (1990). Chinese-English Comparative Study Abroad. In A Collection of Papers on English-Chinese Comparative Studies. Shanghai: Shanghai Foreign Language Education Press.

[5] Lyons, J. (1968). Introduction to Theoretical Linguistics. London: Cambridge University Press.

[6] Olsen M. B. (1997). A semantic and Pragmatic Model of Lexical and Grammatical Aspect. New York \& London: Garland Publishing, Inc.

[7] Richards, J.C. et al. (2000). Longman Dictionary of Language Teaching and Applied Linguistics (trans by Guan Yanhong). Beijing Foreign Language Teaching and Research Press.

[8] Ungerer E. \& H. J. Schmid. (2001). An Introduction to Cognitive Linguistics. Beijing: Beijing Foreign Language Teaching and Research Press.

[9] Wan Bo. (1996). Review of the Researches on Aspect in Modern Chinese. Journal of Jiangxi Normal University, 1, 22-26.

[10] Yi Zhongliang. (1999). Semantic Grammar of English Verbs. Changsha: Hunan Normal University Press.

[11] Zhang Jin, Chen Yunqing. (1981). Outline of English-Chinese Comparative Grammar. Beijing: The Commercial Press.

[12] Zuo Siming. (1997). The Concept of Aspect in Modern Chinese. Journal of Shanghai Normal University, 2, 109-115.

Manfu Duan (1973-- ), male, he is currently pursuing his doctoral degree in Beijing Foreign Studies University. Now he is associate professor in the Foreign Languages College, Inner Mongolia University. His academic interests include sociolinguistics, English teaching methodology and history of linguistic thoughts. 